\title{
Bad Food-Good Food: A Broken Paradigm
}

\section{Mihai D Niculescu*}

UNC Nutrition Research Institute and Department of Nutrition, UNC Gillings School of Global Public Health, University of North Carolina at Chapel Hill, Kannapolis, NC, USA

"Out beyond ideas of wrongdoing and right doing there is a field. I'll meet you there"

\section{Jalāl ad-Dīn Muhammad Balkhī (Rumi) [1]}

We live in a fast-changing environment, no doubt about it. We work fast, we talk fast, and we never sleep enough. We also want to understand things quickly, and we think that we are perfectly able to do it thoroughly. But are we? You will ask what does this have to do with nutrition. Of course it does, and it hurts us very much, either the public or scientists. This editorial is about what I call "a broken paradigm". I am referring to the very notion that, by classifying foods (or nutrients) in "bad" or "good", we can achieve nothing but preventing ourselves from understanding the basis of healthy nutrition.

Here I would like to talk about the caveats associated with how public media disseminates the findings from nutrition studies and about how people understand these messages and react to them. The examples mentioned here are used only to support my argumentation, and by no means are specifically targeting their authors or institutions/ companies for other undisclosed purposes.

\section{Simple Messages Distort Scientific Truth and Bring Unwarranted Generalization}

One of the recurring themes in presenting information in media is that short messages and high impact titles are preferred. A second aspect is that the public expects straightforward answers able to be followed. However, such messages, the shorter they are, the more depart from the reality and the science behind cited studies. Allow me to discuss two such cases.

\section{Case 1 -Vitamin E}

There is no doubt that vitamin $\mathrm{E}$ (tocopherol) is essential to human health, and that functional vitamin $\mathrm{E}$ deficiency (due to either deficient intakes or deficient transport) causes severe neurologic alterations [2]. Although its molecular mechanisms are not completely elucidated, we know today that vitamin $\mathrm{E}$ is an essential link in scavenging reactive oxidative species, in conjunction with vitamin $C$ and $n-3$ polyunsaturated fatty acids [3]. Accordingly, the public message has always been that vitamin E is a "good" nutrient. By consequences, foods rich in vitamin E are also "good". All was nice and quiet until 2004 when meta-analysis studies reported that vitamin E supplementation might increase the risk of gastro-intestinal cancers and overall mortality $[4,5]$. Few years later the SELECT trial (looking at whether vitamin $\mathrm{E}$ and selenium could reduce the risk for prostate cancer) was halted because of lack of benefit [6]. After few years of follow-up, researchers concluded that vitamin E supplementation significantly increased with $17 \%$ the risk of prostate cancer [7].

These findings were followed by the public media, which started a more vigorous campaign in informing about vitamin E. But what were the headlines? "Popular but Dangerous: 3 Vitamins That Can Hurt You" (US News, 2012); "Don't Take Your Vitamins" (The New York Times, 2013); or "Bad News for Beta-Carotene and Vitamin E \& A" (EAT RIGHT AMERICA). For the public it was of little importance that the content of these articles was more nuanced. The titles have made their way into public's mind. Not everyone has the time to read these articles and take the time to think about the real messages embedded within the text. How many of us just browse the news headlines every morning?

\section{Case 2 - Eggs are "bad" (a personal experience)}

Two years ago my son (then 13-year-old) came back from school one day telling me that we should not eat eggs anymore. His physical education teacher, who was also teaching nutrition (but with no background in nutrition!) told the class that, because eggs are too high in cholesterol, they cannot be considered among the top 10 healthier foods. I had to have a very serious conversation with my son about why I believe his teacher was wrong. In a follow-up discussion with the teacher, I raised my serious concerns about what kind of message was that, when addressed to a healthy teenager. And I bet that all the 25 plus kids in the class (and in other classes) would come home and tell their parents the same thing: "eggs are bad". He recognized that, when it comes about eggs, he had to follow recommendations that came from the U.S. Department of Education, and that the content of the nutrition curriculum reflects the official position of the department. But what is the science behind the role of eggs in health and disease?

A recent meta-analysis including 16 studies concluded that egg consumption does not increase CVD risk and cardiac mortality in the general population [8]. However, egg consumption was associated with type-2 diabetes and CVD comorbidity in diabetic subjects. However, as pointed out by the authors, confounding points could not be excluded from this analysis, including an overall high-cholesterol diet in the Western countries from which the participants were recruited in all 16 studies. This point has been previously discussed in the light of the Harvard Egg Study, where it was concluded that the association between eggs and high serum cholesterol was incorrect and unsupported by scientific data [9].

\section{The Problem(s)}

The misrepresentation of scientific truths related to nutrition is stemming from at least two sources. One is the limitations that are inherent to every scientific study. In theory, the results of a study are only representative for the subjects involved, specific only to the outcome sought, and inference about the validity of a study towards other populations should be made with caution (generalization). However, the strength of scientific findings can be enhanced by metaanalysis studies, which look at the significance of results in the context of pooled data from different, independent, studies.

*Corresponding author: Mihai D Niculescu, UNC Nutrition Research Institute and Department of Nutrition, UNC Gillings School of Global Public Health, University of North Carolina at Chapel Hill, Kannapolis, Rm. 2014, 500 Laureate Way, Kannapolis, NC 28027, USA, Tel: +1 (704) 250 5029; Fax: +1 (704) 2505001 ; E-mail: Mihai_Niculescu@unc.edu

Received October 10, 2013; Accepted October 11, 2013; Published October 15 2013

Citation: Niculescu MD (2013) Bad Food-Good Food: A Broken Paradigm. J Nutr Disorders Ther 3: e112. doi:10.4172/2161-0509.1000e112

Copyright: (C) 2013 Niculescu MD, et al. This is an open-access article distributed under the terms of the Creative Commons Attribution License, which permits unrestricted use, distribution, and reproduction in any medium, provided the original author and source are credited. 
Another problem in interpreting the data comes from the inherent variations in individual responses to interventions using either nutritional supplements or specific foods. Most epidemiological studies are still using classical statistical methods, where the outcome is tested for statistical significance within a group of subjects. However, this tells little, if anything, about whether the intervention is influencing all participants or only a subgroup. The issue of responders and nonresponders, although well known for a long time in nutrition and pharmacological sciences, is still not enough explored. In other words the generalization of results might not even apply to the entire group involved in a study. Therefore, a second layer of analysis might be necessary to look at subgroups exposed, and assess the differential responses that characterize such subgroups. This does not mean that the results are not telling. They are what they are, but the way of interpreting them (in terms of population at risk) still has a long way to become relevant to each and every individual. This brings me to another point of the problem.

The public becomes aware that, for instance, the use of vitamin $\mathrm{E}$ at 17 times higher doses than the recommended intakes, would increase the risk for prostate cancer by $17 \%$. Suddenly, the public realizes (or perceives) that vitamin E might be "bad". Same for gastro-intestinal cancers [4]. In the SELECT study, 529 subjects out of 8,696 (6.08\%) developed prostate cancer, as compared to the higher rate of 620 out of $8737(7.12 \%)$ in the vitamin $\mathrm{E}$ group. This means that the distributed risk among every 100 men, due to vitamin E supplementation, would be $1.04 \%$. It means, statistically, that 1.04 person(s) out of 100 might get prostate cancer as a result of the supplementation with vitamin E. This is just an example of how different numbers can represent the same scientific fact, and this is important when data is presented to the public.

Several open questions are still in the air:

- Are all the men within the study group at the same risk?

- What is the risk for other age categories?

- What other factors are contributing to the individual response (not assessed by now at individual levels) related to a specific intervention?

- Is vitamin E supplementation beneficial against other pathologic states? And to whom?

Only by addressing these, and maybe other questions, one could have a complete image about the beneficial or deleterious effects of a nutrient/food/nutriceutical.

Another issue (exemplified by the second case) is that public messages endorsed by official forums are not necessarily accurate. While egg consumption might be harmful to diabetic children, there are no scientific grounds why a healthy child would not consume eggs (which are also high in other nutrients required for normal development). Again, this is another example of using a blanket message, while the intended audience should be only a subgroup at risk.

But we still have a long road ahead in defining who would benefit, and who could be harmed, by the consumption of specific foods or nutrients. We have just started a long road which, hopefully, will bring us closer to really understanding our responses to nutrition. Genetics, epigenomics, metabolomics, and other systems biology fields could provide the breakthrough required to correctly define individualized nutrition requirements, in conjunction with gene-environment interactions. Until then, I wish that public media and educators be more selective and more specific in regard to their nutrition messages. I also wish the public to take the time and think about these messages and, most of all, refrain from drawing superficial conclusions. Let us go beyond the naïve thinking that foods are "bad" or "good", and rather think about foods that are adequate for an individual, at a certain stage in his or her life.

\section{References}

1. Barks C (2007) RUMI: THE BOOK OF LOVE: Poems of Ecstasy and Longing HarperCollins Publishers Inc.

2. Niki E, Traber MG (2012) A history of vitamin E. Ann Nutr Metab 61: 207-212.

3. Rodrigo R, Prieto JC, Castillo R (2013) Cardio protection against ischaemia/ reperfusion by vitamins $\mathrm{C}$ and $\mathrm{E}$ plus $\mathrm{n}-3$ fatty acids: molecular mechanisms and potential clinical applications. Clin Sci (Lond) 124: 1-15.

4. Bjelakovic G, Nikolova D, Simonetti RG, Gluud C (2004) Antioxidant supplements for prevention of gastrointestinal cancers: a systematic review and meta-analysis. Lancet 364: 1219-1228.

5. Miller ER, Pastor-Barriuso R, Dalal D, Riemersma RA, Appel LJ, et al. (2005) Meta-analysis: high-dosage vitamin $E$ supplementation may increase all-cause mortality. Ann Intern Med 142: 37-46.

6. Lippman SM, Klein EA, Goodman PJ, Lucia MS, Thompson IM, et al. (2009) Effect of selenium and vitamin $E$ on risk of prostate cancer and other cancers: the Selenium and Vitamin E Cancer Prevention Trial (SELECT). JAMA 301 $39-51$.

7. Klein EA (2011) Vitamin E and the risk of prostate cancer: the Selenium and Vitamin E Cancer Prevention Trial (SELECT). JAMA 306: 1549-1556.

8. Shin JY, Xun P, Nakamura Y, He K (2013) Egg consumption in relation to risk of cardiovascular disease and diabetes: a systematic review and meta-analysis. Am J Clin Nutr 98: 146-59.

9. Jones PJ (2009) Dietary cholesterol and the risk of cardiovascular disease in patients: a review of the Harvard Egg Study and other data. Int J Clin Pract Suppl 163: 1-8. 